\title{
Applicability of the Compound Independent Calibration Method for the Chromatographic Quantitation of Trihalomethanes with
}

\section{Atomic Emission Detection}

\author{
Fabio Augusto and Antonio Luiz Pires Valente* \\ Instituto de Química - UNICAMP, C.P. 6154, 13083-970 Campinas - SP, Brazil
}

Received: July 17, 1996

\begin{abstract}
Foi estudada a aplicabilidade do método de calibração independente de composto para a análise cromatográfica de quatro trialometanos (THM) com detecção por um Detector por Emissão Atômica em Plasma de Hélio Induzido por Microondas (MIP). A sistemática usada se baseou na comparação de curvas de calibração construídas para os quatro THM monitorando o sinal nas raias de emissão de cloro e carbono. Os resultados desses estudos também permitiram avaliar a utilidade do detector MIP para a análise dos THM em concentrações ambientais típicas.

The applicability of the compound independent calibration method for the chromatographic analysis of four trihalomethanes (THM) after detection with a Microwave Induced Helium Plasma Atomic Emission Detector (MIP) was studied. The approach used was based on comparison of calibration curves constructed for the THM after monitoring the MIP signal at a carbon emission line and a chlorine emission line. The results of these studies also allowed evaluation of the usefulness of the MIP detector for the analysis of the THM at typical concentration levels of environmental concern.
\end{abstract}

Keywords: gas chromatography; atomic emission detection; compound independent calibration; trihalomethanes

\section{Introduction}

Analysis of trihalometane (THM) water pollutants is usually undertaken using the Electron Capture Detector (ECD) due to its sensitivity and selectivity towards halogenated compounds. In these analysis the selectivity of the of the ECD towards the THM is exploited to provide chromatograms in which the THM peaks can be quantified without interference of extraneous peaks. The Microwave Induced Helium Plasma Atomic Emission Detector (MIP) is another selective detector that has advantageous characteristics that may be exploited in the analysis of the THM.

The MIP is an element-selective detector which enables differentiation among the several THM according to the monitored halogen emission line. The MIP generally shows high sensitivity at a carbon emission line (e.g. $247.9 \mathrm{~nm})^{1}$. Thus, if the peak obtained for a THM at a given halogen emission line is not adequate for reliable quantitative analysis the possibility exists that the chromatogram obtained at the carbon line may be used for this quantitation. The use of the carbon emission line would demand the identification of the proper THM peak within possible non THM peaks. Such identification can be appropriately done by using the retention time of the same peak measured in a chromatogram obtained at the selective halogen emission line, or if possible, compare simultaneously obtained chromatograms.

The MIP has potential for permitting the use of the so called compound independent calibration method, so that after proper adjustment of the MIP operational conditions its response towards structurally different compounds may statistically merge to a common value $e^{2,3}$. In this case it would be possible to quantitate a given THM using the calibration curve of another THM - which would be very advantageous if the first THM is not available as an analytical standard.

In the present paper chloroform, bromodichloromethane, dibromochloromethane and bromoform were used as test compounds for the construction of calibration curves at the carbon $247.9 \mathrm{~nm}$ emission line and at the 
chlorine $479.5 \mathrm{~nm}$ emission line. To access the feasibility of quantitation of each of the studied THM using the calibration curve of any of the other three THM, "overall" calibration curves were constructed. These overall calibration curves are composed of the response data of the four compounds obtained at the $\mathrm{C}$-line or at the $\mathrm{Cl}$-line, in relation to the corresponding detected mass of carbon or of chlorine. The overall $\mathrm{C}$-line and $\mathrm{Cl}$-line calibration curves were statistically compared with the corresponding individual calibration curves obtained for the four studied THM to confirm the possibility of using the compound independent calibration method.

\section{Experimental}

Instrumentation: The lab-made GC-MIP consisted of an Enhanced Beenaker $\mathrm{TM}_{010}$ resonant cavity and a $G M W$ 24-303DR 2.45 MHz microwave generator (AHF Analisentechnik, Tubingen, Germany). The discharge cell used in all experiments was made of a quartz tube of $5 \mathrm{~mm}$ o.d. and $3 \mathrm{~mm}$ i.d. The plasma gas was grade 4.7 helium (Air Products and Chemicals, Allentown, PA). The monitoring and conditioning of the MIP signal was accomplished with a Multispec II grating monochromator of $12.5 \mathrm{~cm}$ focal length (Oriel Co., Stratford, CT), a model 77344 photomultiplier tube (Oriel) and a model 7070 high voltage supply \& amplifier (Oriel). The MIP was interfaced to a HP-5890 gas chromatograph (Hewlett-Packard, Avondale, PA) through a heated transfer line.

Data collection and analysis: The MIP Signal was digitized by a model $D T-2801 A 12$ bit AD converter (Data Translation, Marlboro, MA) connected to a PC-type microcomputer. The A-to-D data conversion was made at $20 \mathrm{~Hz}$. The chromatographic data analisys was accomplished with a self-developed software written in $\mathrm{Pascal}^{4}$.

Test mixtures: Isooctane solutions of the THM: chloroform, bromodichloromethane, dibromochloromethane and bromoform. The concentrations of the test solutions were adjusted to have the following detected masses: 15.2 to $35.5 \mathrm{ng} \mathrm{CHCl}_{3}, 21.1$ to $36.9 \mathrm{ng} \mathrm{CHBrCl}_{2}, 15.3$ to 35.6 ng $\mathrm{CHBr}_{2} \mathrm{Cl}$ and 15.9 to $37.1 \mathrm{ng} \mathrm{CHBr}_{3}$.

Chromatographic conditions: Column: SE-30 crosslinked methylsilicone FS capillary column, $30 \mathrm{~m}$ long, $\mathrm{d}_{\mathrm{i}}=$ $0.25 \mathrm{~mm}, \mathrm{~d}_{\mathrm{f}}=0.25 \mathrm{~m}$ (Alltech, Deerfield, IL). Injected volume $=0.2 \mu \mathrm{L}$. Carrier gas $(\mathrm{He})$ flow $=0.9 \mathrm{~mL} \mathrm{~min}^{-1}$. Split ratio $=1: 96(\mathrm{C}), 1: 95(\mathrm{Cl})$. Column temperature $=$ $40{ }^{\circ} \mathrm{C}$ to $96{ }^{\circ} \mathrm{C}$ at $7.5{ }^{\circ} \mathrm{C} \cdot \mathrm{min}^{-1}$. Injector temperature $=$ $240{ }^{\circ} \mathrm{C}$. Transfer line temperature $=200{ }^{\circ} \mathrm{C}$. All injections were performed in triplicate.

Plasma conditions: flow of plasma support gas $(\mathrm{He})=$ $150 \mathrm{~mL} \mathrm{~min}^{-1}(\mathrm{C})$ and $1500 \mathrm{~mL} \mathrm{m^{-1 }}(\mathrm{Cl})$; microwave forward power $=60 \mathrm{~W}(\mathrm{C})$ and $200 \mathrm{~W}(\mathrm{Cl})$. Spectrometric conditions: monitored emission analytical lines $=247.9 \mathrm{~nm}$ (C) and $475.5 \mathrm{~nm}(\mathrm{Cl})$; monochromator entrance and exit slit widths $=0.1 \mathrm{~mm}, \mathrm{H} . \mathrm{V}$. to the photomultiplier tube $=$ $900 \mathrm{~V}$, electrometer gain $=1 \times 10^{-7} \mathrm{~A} \mathrm{~V}^{-1}$ to $5 \times 10^{-9} \mathrm{~A} \mathrm{~V}^{-1}$.

\section{Results and Discussion}

The MIP conditions of input power and helium flow at both the $\mathrm{C}$-line and the $\mathrm{Cl}$-line, specified in the Experimental, were defined by previous characterization experiments with the MIP system using test mixtures that did not include the $\mathrm{THM}^{3}$. Using these conditions, triplicate chromatograms were obtained for each mass of carbon and chlorine of each of the four THM. Figure 1 depicts two of the obtained chromatograms. For each THM the sets of data pairs of Area vs Mass ( of $\mathrm{C}$ or $\mathrm{Cl}$ ) were submitted to data analysis by linear regression to establish the slope, $\mathrm{S}$, the intercept, I, and the correlation coefficient, $r$, of the regression equation $\mathrm{A}=\mathrm{S} \cdot \mathrm{m}_{\mathrm{E}}+\mathrm{I}$, were $\mathrm{m}_{\mathrm{E}}$ is the detected mass of carbon or chlorine. The slopes and the intercepts, with their standard deviations and correlation coefficients, for the seven calibration curves are shown in Table 1. The Area vs Mass data of all compounds obtained at the C-line were grouped and submitted to the same data analysis for the calculation of S, I and $\mathrm{r}$ of the C-line overall regression equation. The same procedure was applied to the Cl-line data to obtain the Cl-line overall regression equation. The $\mathrm{S}$ and I (and respective standard deviations) and $\mathrm{r}$ of the two overall curves are also shown in Table 1. The C-line and Cl-line overall calibration curves are shown in Fig. 2.

The comparison of the four individual C-line calibration curves with the overall $\mathrm{C}$-line calibration curve was done using a two step calculation approach. Firstly it was established that the data interpolation done with the overall calibration curve was as reliable as the interpolation done with the corresponding individual calibration curves. This

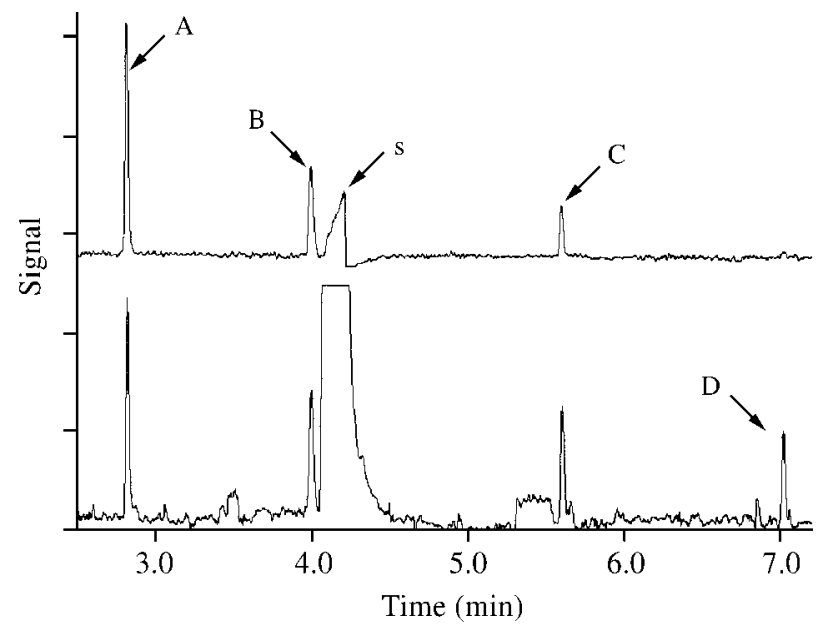

Figure 1. Typical chromatograms of the THM test mixture at the Cl-line (above) and at the $\mathrm{C}$-line (below). Peak identification and detected masses: $\mathrm{A}=25.4 \mathrm{ng}$ of $\mathrm{CHCl}_{3}(2.6 \mathrm{ng}$ of $\mathrm{Cl}, 22.7 \mathrm{ng}$ of $\mathrm{C}), \mathrm{B}=26.4 \mathrm{ng}$ of the $\mathrm{CHBrCl}_{2}$ (1.9 ng of Cl, $11.4 \mathrm{ng}$ of $\mathrm{C}$ ), $\mathrm{s}=$ isooctane (solvent), $\mathrm{C}=25.4 \mathrm{ng}$ of $\mathrm{CHBr}_{2} \mathrm{Cl}$ (1.5 $\mathrm{ng}$ of $\mathrm{Cl}, 4.3 \mathrm{ng}$ of $\mathrm{C}$ ), $\mathrm{D}=26.5 \mathrm{ng}$ of $\mathrm{CHBr}_{3}$ (1.3 $\mathrm{ng}$ of $\mathrm{Cl})$. 
Table 1. Regression Parameters of the Individual Calibration Curves (under the formulae of the THM) and of the Overall Calibration Curves Obtained at the Carbon and Chlorine Emission Lines.

\begin{tabular}{|c|c|c|c|c|c|c|}
\hline & & $\mathrm{CHCl}_{3}$ & $\mathrm{CHBrCl}_{2}$ & $\mathrm{CHBr}_{2} \mathrm{Cl}$ & $\mathrm{CHBr}_{3}$ & Overall \\
\hline & $\mathrm{S}$ & $1.57 \pm 0.07$ & $1.86 \pm 0.08$ & $1.77 \pm 0.08$ & $1.2 \pm 0.1$ & $1.52 \pm 0.04$ \\
\hline C Line & I & $2 \pm 2$ & $-7 \pm 2$ & $0 \pm 1$ & $7 \pm 2$ & $3 \pm 1$ \\
\hline \multirow[t]{3}{*}{$247.9 \mathrm{~nm}$} & $\mathrm{r}$ & 0.997 & 0.998 & 0.997 & 0.980 & 0.994 \\
\hline & $\mathrm{n}^{\mathrm{a}}$ & 5 & 4 & 5 & 5 & 15 \\
\hline & $\mathrm{S}$ & $47 \pm 2$ & $60 \pm 2$ & $52 \pm 2$ & - & $47 \pm 2$ \\
\hline Cl Line & I & $4 \pm 4$ & $-3 \pm 2$ & $6 \pm 1$ & - & $7 \pm 2$ \\
\hline \multirow[t]{2}{*}{$479.5 \mathrm{~nm}$} & $\mathrm{r}$ & 0.995 & 0.998 & 0.999 & - & 0.992 \\
\hline & $\mathrm{n}$ & 5 & 6 & 4 & - & 16 \\
\hline
\end{tabular}

$\mathrm{a}=$ number of data points (each with triplicate injections) used to construct the calibration curve.
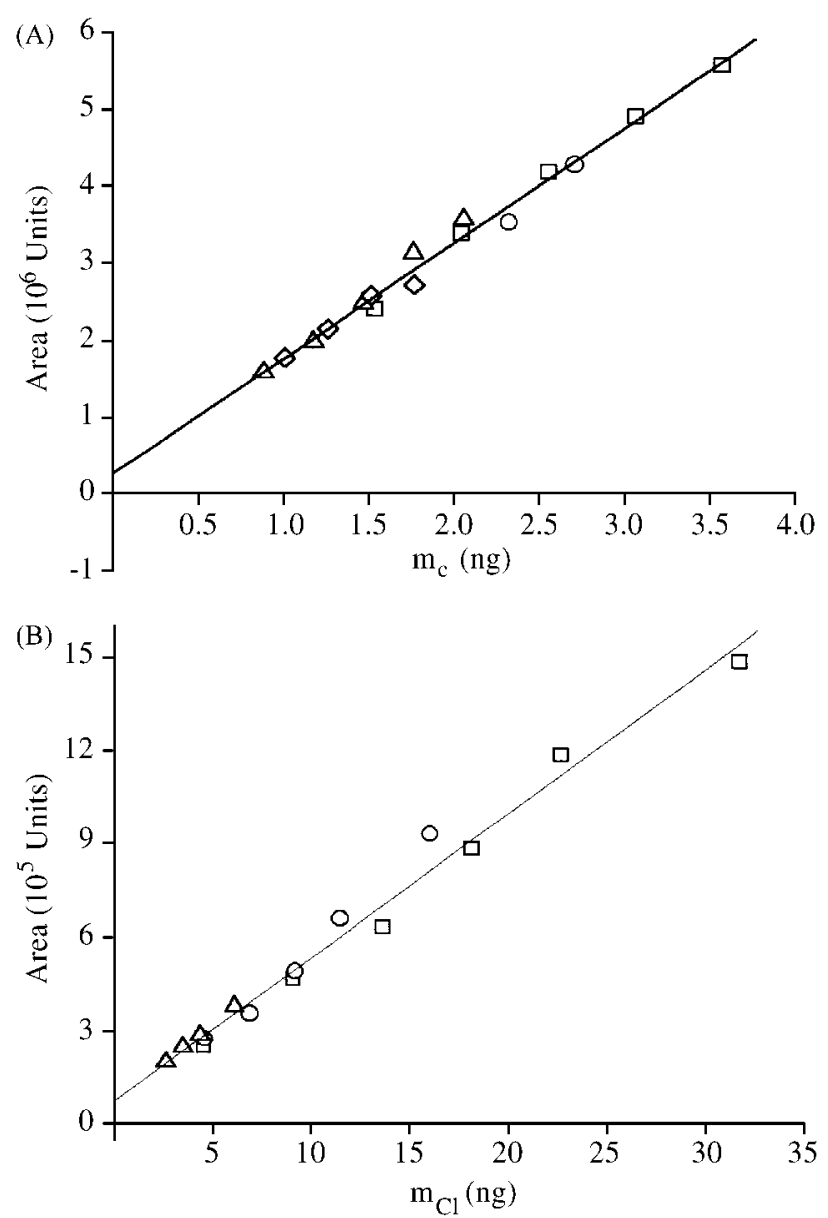

Figure 2. Overall calibration curves obtained at: (A) the $\mathrm{C}$-line, (B) the Cl-line. $\square=\mathrm{CHCl}_{3}, \mathrm{O}=\mathrm{CHBrCl}_{2}, \Delta=\mathrm{CHBr}_{2} \mathrm{Cl}, \mathrm{G}=\mathrm{CHBr} 3$.

first step of the calculation was based on the statistical comparison of the relative residual defined in Eq. 1.

$$
R R=100 \frac{\left|<A>_{I}-A_{I}\right|}{A_{I}}
$$

were $A_{I}$ represents each of the experimental areas used to establish the calibration curve and $<\mathrm{A}_{\mathrm{I}}>$ represents the area interpolated for each detected mass using the regression equation of the corresponding calibration curve. Sets of RR were calculated for each individual calibration curve and for the two overall calibration curves - the number of RR in each set is equal to the number of Area vs Mass data pairs, $n$, shown in Table 1 . Then each set of RR was averaged and the Student- $t$ confidence interval ${ }^{5}$ at the $95 \%$ confidence level was calculated for each average RR. A similar analysis was carried out fot the three chlorine containing compounds at the $\mathrm{Cl}$-line. The results of these calculations are shown in Table 2.

As can be seen in Table 2 for the Cl-line data, when the confidence interval is taken into account, the average RR of the overall calibration curve ranges from 4 to $8 \%$ while for the individual calibration curve RR ranges from 1 to 5 $\%$. Thus, the range of the RR for the overall curve overlap with the range of the $\mathrm{RR}$ for the individual curves $\left(\mathrm{CHCl}_{3}\right.$, $\mathrm{CHBrCl}_{2}, \mathrm{CHBr}_{2} \mathrm{Cl}$ ). It may therefore be concluded that the interpolations made with the $\mathrm{Cl}$-line overall calibration curve are as reliable as the interpolations made with either of the three individual calibration curves. The data of Table 2 shows that the same conclusion also applies to the C-line data.

As the aforementioned comparison indicated that the studied calibration curves are equally reliable for interpolation purposes the second step of the calculation was performed to determine if an interpolation done with the C-line overall calibration curve would result in a chromatographic area statistically equal to the area interpolated with any of the four individual C-line calibration curves. The same comparison was applied to compare the Cl-line overall calibration curve with the three corresponding $\mathrm{Cl}$ line calibration curves. The basis for the comparison was the parameter $\Delta$ defined in Eq. 2 . 
Table 2. Average relative residuals used to establish the reliability of the $\mathrm{C}$-line and $\mathrm{Cl}$-line individual calibration curves and overall calibration curves.

\begin{tabular}{lcc}
\hline Emission Line & $\begin{array}{c}\text { Overall calibration } \\
\text { curve }\end{array}$ & $\begin{array}{c}\text { Individual } \\
\text { calibration curve }\end{array}$ \\
\hline $\mathrm{C}-247.9 \mathrm{~nm}$ & $(2 \pm 1) \%$ & $(2 \pm 1) \%$ \\
$\mathrm{Cl}-479.5 \mathrm{~nm}$ & $(6 \pm 2) \%$ & $(3 \pm 2) \%$ \\
\hline
\end{tabular}

$$
\Delta=100 \frac{<\mathrm{A}_{\mathrm{G}}>-<\mathrm{A}_{\mathrm{I}}>}{<\mathrm{A}_{\mathrm{I}}>}
$$

The $\Delta$ parameter was determined for each of the detected $\mathrm{m}_{\mathrm{E}}(\mathrm{C}$ and $\mathrm{Cl})$ and the average, $\Delta_{\mathrm{m}}$, of each set of $\Delta$ $(\mathrm{C}$ or $\mathrm{Cl})$ was calculated together with its confidence interval. As can be deduced after inspection of Eq. 2, $\Delta$ expresses, for the $\mathrm{C}$ and $\mathrm{Cl} \mathrm{m}_{\mathrm{E}}$ and for each of the THM, the difference between the overall equation-interpolated chromatographic area and the individual equation interpolated chromatographic area. Thus, whenever $\Delta_{\mathrm{m}}$ is statistically null it may be concluded that no difference exists between the overall-equation interpolated chromatographic area and the individual equation-interpolated area. Such a conclusion proved to be valid for the THM response data at both the $\mathrm{C}$-line and the $\mathrm{Cl}$-line as their $\Delta_{\mathrm{m}}$ statistics were, respectively, $\Delta_{\mathrm{m}(\mathrm{C})}=(0 \pm 4) \%$ and $\Delta_{\mathrm{m}(\mathrm{Cl})}=(1 \pm 8) \%$.

The Minimum Detectable Level, MDL, in pg of Carbon, pg of Chlorine and of pg of THM, at the C-line and at the $\mathrm{Cl}$-line were ascertained using the calibrations curves and are shown in Table 3.

It is of value to consider the data of Table 3 in view of the analytical methodology recommended by EPA for the chromatographic analysis of the purgeable fraction of water contaminants ${ }^{6}$. In this EPA methodology $5.0 \mathrm{~mL}$ of water is processed by purge-and-trap to provide a recovery of purgeable contaminants; in similar processes, recoveries are reported to be at a level of $80 \%$ or more ${ }^{7}$. If the lower level of $80 \%$ of recovery is considered the MDL of Table 3 would allow the quantitation of THM dissolved in water samples at the following concentrations: $0.03 \mu \mathrm{g} \mathrm{L}^{-1}$ of $\mathrm{CHCl}_{3}, 0.07 \mu \mathrm{g} \mathrm{L}^{-1}$ of $\mathrm{CHBrCl}_{2}, 0.11 \mu \mathrm{g} \mathrm{L}^{-1}$ of $\mathrm{CHBr}_{2} \mathrm{Cl}$

Table 3. Minimum Detectable Levels, in pg, for the THM chromatographic analysis calculated with the calibration curves of Table 1.

\begin{tabular}{lcccc}
\hline & \multicolumn{2}{c}{$\mathrm{C}-247.9 \mathrm{~nm}$} & \multicolumn{2}{c}{$\mathrm{Cl}-479.5 \mathrm{~nm}$} \\
\hline Compound & Carbon & THM & Chlorine & THM \\
\hline $\mathrm{CHCl}_{3}$ & 25 & 250 & 105 & 120 \\
$\mathrm{CHBrCl}_{2}$ & 38 & 520 & 120 & 280 \\
$\mathrm{CHBr}_{2} \mathrm{Cl}$ & 26 & 450 & 86 & 500 \\
$\mathrm{CHBr}_{3}$ & 38 & 810 & - & - \\
\hline
\end{tabular}

and $0.20 \mu \mathrm{g} \mathrm{L}^{-1}$ of $\mathrm{CHBr}_{3}$ (such values refer to the quantitation of bromoform at the $\mathrm{C}$-line and quantitation of the three chlorinated THM at the Cl-line). These detectable concentrations compare favorably with the minimum detectable concentrations given by the EPA method using an ECD which are: $0.05 \mu \mathrm{g} \mathrm{L}^{-1}$ of $\mathrm{CHCl}_{3}, 0.10 \mu \mathrm{g} \mathrm{L}^{-1}$ of $\mathrm{CHBrCl}_{2}, 0.09$ $\mu \mathrm{g} \mathrm{L}^{-1}$ of $\mathrm{CHBr}_{2} \mathrm{Cl}$ and $0.20 \mu \mathrm{g} \mathrm{L}^{-1}$ of $\mathrm{CHBr}_{3}{ }^{6}$. Thus it may be concluded that the GC-MIP equipment used in the above described studies is adequate for the chromatographic analysis of these THM at the levels recommended in the EPA methodology.

\section{Conclusions}

In these studies of THM quantitation by GC-MIP it was possible to achieve an adjustment of the chromatographic system to allow the use of the compound independent calibration method. It was also established that the MIP detector is adequate for the quantitation of the THM at concentrations similar to those recommended by the EPA protocol. This indicates that the MIP may be used in actual THM analysis as a compound-independent detector.

\section{Acknowledgment}

The authors want to thank to FAPESP for grant no. 92/4880-7, which allowed the present work.

\section{References}

1. Uden, P.C. In Element Specific Chromatographic Detection by Atomic Emission Spectroscopy; ACS Symposium Series \#479; American Chemical Society, Washington, 1979.

2. Johnson, D; Quimby, B.; Sullivan, J.J. Am.Lab. 1995, $27,13$.

3. Augusto, F.; Valente, A.L.P. J. High Resolut. Chromatogr. submitted for publication, 1996.

4. Augusto, F. M.Sc. Dissertation; Universidade Estadual de Campinas; Brazil, 1990, pp. 38 to 39.

5. Miller, J.C.; Miller, J.N. In Estadística para Química Analítica; $2^{\text {nd }}$ ed.; Addison-Wesley Iberoamericana; Wilmington, 1993, pp. 40 to 41.

6. Environmental Protection Agency, United States of America: Guidelines Establishing Test Procedures for the Analysis of Pollutants under Clean Water Act; Final Rule and Interim Final Rule and Proposed Rule; Part 136; Apendix A; Method 601 ("Purgeable Halocarbons"). Federal Register, 49 (209), 10/26/1984, pp. 29 to 40 .

7. Ioffe, B.V.; Vitenberg, A.G. In Head-Space Analysis and Related Methods in Gas Chromatography.

FAPESP helped in meeting the publication costs of this article 